Paula Mancini C. Mello Ribeiro

\title{
Um real em jogo A função do pai e o sujeito na clínica
}

\section{TESE DE DOUTORADO}

\section{DEPARTAMENTO DE PSICOLOGIA}

Programa de Pós-Graduação em Psicologia Clínica 


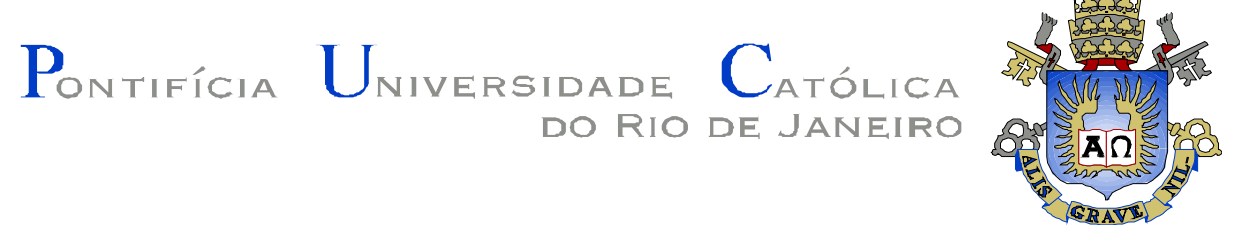

Paula Mancini Cordeiro de Mello Ribeiro

\author{
Um real em jogo \\ A função do pai e o sujeito na clínica
}

Tese de Doutorado

Dissertação apresentada ao Programa de PósGraduação em Psicologia Clínica da PUC-Rio como requisito parcial para obtenção do título de Doutor em Psicologia.

Orientador: Marcus André Vieira

Rio de Janeiro

Fevereiro de 2006 


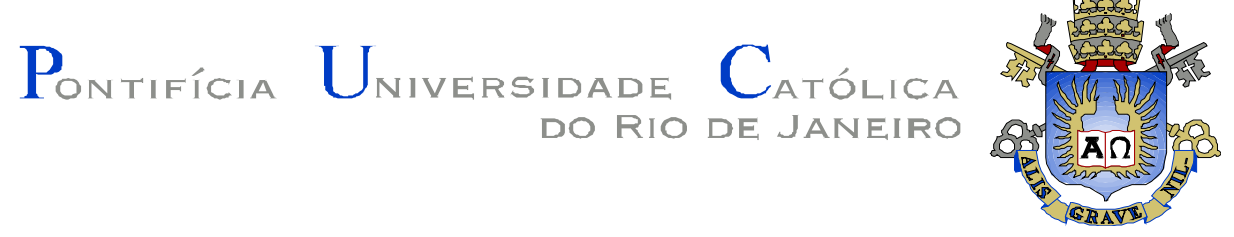

Paula Mancini Cordeiro de Mello Ribeiro

\section{Um Real em Jogo: A função do pai e o sujeito na clínica}

Tese apresentada como requisito parcial para obtenção do grau de Doutor pelo Programa de Pós-Graduação em Psicologia Clínica do Departamento de Psicologia do Centro de Teologia e Ciências Humanas da PUC-Rio. Aprovada pela Comissão Examinadora abaixo assinada.

Profo. Marcus André Vieira

Orientador

Departamento de Psicologia - PUC-Rio

Profa. Ana Maria Rudge Departamento de Psicologia - PUC-Rio

Profa . Anna Carolina Lo Bianco Clementino Centro de Filosofia e Ciências Humanas - UFRJ

Prof ${ }^{\circ}$. Francisco Leonel de Figueiredo Fernandes

Departamento de Psicologia - UFF

Profo. Antônio Márcio Ribeiro Teixeira Departamento de Psiquiatria e Neurologia - UFMG

Prof. Paulo Fernando Carneiro de Andrade Coordenador Setorial de Pós-Graduação e Pesquisa do Centro de Teologia e Ciências Humanas - PUC-Rio

Rio de Janeiro, 17 de fevereiro de 2006 
Todos os direitos reservados. É proibida a reprodução total ou parcial do trabalho sem autorização da universidade, da autora e do orientador.

\section{Paula Mancini Cordeiro de Mello Ribeiro}

Graduou-se em Psicologia na Pontifícia Universidade Católica do Rio de Janeiro em 1991, cursou a Especialização em Psicologia Clínica na PUC-RJ de 1992 a 1994, é mestre em Teoria Psicanalítica pelo Programa de Pós Graduação em Teoria Psicanalítica na Universidade Federal do Rio de Janeiro desde 1997. Desenvolve desde 1999 vários projetos de atendimento psicanalítico a crianças, adolescentes e autores de agressão em situações de violência doméstica e risco social, assim como de capacitação para diversos profissionais da rede pela Organização Não-Governamental Núcleo de Atenção à Violência (NAV) no Município do Rio de Janeiro. É membro do Tempo Freudiano Associação Psicanalítica desde 1997.

Ficha Catalográfica

Ribeiro, Paula Mancini C. Mello

Um real em jogo : a função do pai e o sujeito na clínica / Paula Mancini C. Mello Ribeiro ; orientador: Marcus André Vieira. - Rio de Janeiro : PUC, Departamento de Psicologia, 2006.

151 f. ; $30 \mathrm{~cm}$

Tese (doutorado) - Pontifícia Universidade Católica do Rio de Janeiro, Departamento de Psicologia.

Inclui referências bibliográficas.

1. Psicologia - Teses. 2. Função do pai. 3. Clínica. 4. Real. 5. Simbólico. 6. Imaginário. 7. Sujeito. I. Vieira, Marcus André. II. Pontifícia Universidade Católica do Rio de Janeiro. Departamento de Psicologia. III. Título. 


\section{Agradecimentos}

Ao CNPQ e à PUC-Rio, pelos auxílios concedidos, necessários para a realização deste trabalho.

A Marcus André Vieira, pela orientação e pelas pontuações precisas, que me fizeram repensar e melhor articular a questão trabalhada.

Aos professores de Pós-Graduação do Departamento da PUC-Rio, em especial a Junia Vilhena e a Ana Maria Rudge, que insistiram em que eu privilegiasse a articulação com a clínica.

A Maria Idália de Góes, pela fundamental importância de sua escuta e interlocução para a minha articulação das questões com a clínica.

À equipe do NAV, Simone Gryner, Raquel Oliveira, Flávia Franco, Bárbara de Souza, Marisa Solberg, Rosemary Pinto, Laurinda Freitas, Adriana Pacheco, Renata Monteiro, Ingrid Dakó, pela garra e pelo trabalho precioso.

Ao Tempo Freudiano, lugar onde eu exerço e aprendo o meu trabalho, em especial a Antônio Carlos Rocha. E também a alguns outros que marcam meu percurso: Fernanda CostaMoura, Ana Cristina Manfroni, Eduardo Rocha, Francisco Leonel Fernandes, Dionysia Rache de Andrade, Anna Carolina Lo Bianco, Pedro Duarte Silveira e Luís Romão. A Juliana de Miranda e Castro pelas traduções e a Joana Barros pela ajuda com algumas referências.

A Sandra Niskier Flanzer, pela leitura cuidadosa e disponibilidade de ajuda sempre que foi preciso.

A Raquel Oliveira, pela companhia e valiosa interlocução que sempre fazem muita diferença pra mim.

A Mônica Magalhães, pela escuta carinhosa e sempre muito fina não só nos meus últimos momentos de escrita dessa tese, mas sempre.

A Simone Gryner, por sustentar a direção analítica na coordenação do NAV, pelo valor dado à palavra não só no trabalho, mas por me lembrar dele também na minha vida.

A Luiz Eduardo, pela revisão preciosa.

Ao meu marido Guilherme e aos meus filhos Igor e Joana, pelo amor, carinho, companhia e força, que, muitas vezes, traduziram-se pela frase: "Mãe, vai em frente!" 


\section{Resumo}

Ribeiro, Paula Mancini Cordeiro de Mello. Um real em jogo - a função do pai e o sujeito na clínica. Rio de Janeiro, 2006. 151p. Tese de Doutorado - Departamento de Psicologia, Pontifícia Universidade Católica do Rio de Janeiro.

Parte-se de um trabalho de atendimento psicanalítico a crianças, adolescentes e autores de agressão em situações de violência doméstica, que se insere em um contexto atual de declínio da função paterna. A complexidade dessa função do pai é trabalhada a partir de Freud e principalmente com Lacan. A partir da leitura estrutural de Lacan da questão paterna, com as noções de significante, Nome do Pai e dos três registros do real, simbólico e imaginário, situa-se a diferença que se coloca na clínica psicanalítica quando não se reduz a complexidade em jogo na função do pai para o sujeito.

Palavras-chave: Função do Pai, Clínica, Real, Simbólico, Imaginário, Sujeito. 


\section{Resume}

Ribeiro, Paula Mancini Cordeiro de Mello. Um real em jogo - a função do pai e o sujeito na clínica. Rio de Janeiro, 2006. 151p. Tese de Doutorado - Departamento de Psicologia, Pontifícia Universidade Católica do Rio de Janeiro.

On est parti d'un travail psychanalytique avec des enfants, adolescents et auteurs des agressions dans des situations de violence em famille, qui s'insérent dans le contexte actuel de déclin de la fonction paternelle. La complexité de cette fonction du père est travaillé avec Freud et surtout avec Lacan. À partir de la lecture structurale de Lacan de la question paternelle, avec les notions de signifiant, Nom du Père et les trois registres du réel, symbolique et imaginaire, on situe ce qui se produit dans la clinique psychanalytique quand on ne reduit pas la complexité en jeu dans la fonction du père au sujet.

Mots Clés: Fonction du Père, Clinique, Réel, Symbolique, Imaginaire, Sujet 


\section{Sumário}

$\begin{array}{ll}\text { Introdução } & 8\end{array}$

Capítulo 1 - Freud e a realidade do pai 14

1.1 O pai na teoria da sedução e na fantasia 14

A fantasia originária $\quad 18$

A fantasia do "bate-se em uma criança" 23

A cena traumática e o significante paterno com Lacan 27

1.2 O pai e a questão da origem da lei - uma releitura de Lacan dos mitos de Freud 29

Édipo e o saber $\quad 30$

Totem e Tabu e a origem $\quad 35$

Moisés e a heterogeneidade do pai $\quad 39$

Capítulo 2 - A metáfora paterna e o Nome do Pai 47

2.1 A criança e o Nome do Pai 49

A etapa fálica primitiva $\quad 51$

A metáfora paterna $\quad 54$

O falo na família $\quad 57$

A cadeia de filiação e o desejo $\quad 60$

2.2 O adolescente e a metáfora paterna $\quad 67$

O momento de ruptura ou pane do Outro 68

A importância do social no momento da adolescência $\quad 78$

Capítulo 3 - RSI, o sujeito e o pai 85

3.1 Situações clínicas 86

3.2 Pai real em Hans. A articulação: real, simbólico e imaginário 90

3.3 Hans e a estrutura do ato 96

3.4 A saída de Hans da fobia e a posição de seus pais 102

3.5 O real na função do pai 106

Capítulo $4-0$ ato, o sujeito e o pai $\quad 115$

$\begin{array}{ll}\text { 4.1 Um lugar na cultura - algumas observações sobre } & \\ \text { o pai e a religião a partir de Freud e Lacan } & 116\end{array}$

O contexto de onde o pai tira sua autoridade 119

As transformações da modernidade $\quad 120$

4.2 A clínica e o sujeito 122

A transferência e o ato analítico 123

O passo do sujeito: prescinde-se do pai? 126

A clínica e o sujeito $\quad 130$

5 - Conclusão 138

6 - Referências Bibliográficas 143 